\title{
Interfacial Reactions between Oxygen Containing Fe and Al at the Onset of Liquid Fe Deoxidation by Al Addition
}

\author{
Marie-Aline VAN ENDE, ${ }^{1,2)}$ Muxing GUO, ${ }^{1)}$ Joris PROOST, ${ }^{2)}$ Bart BLANPAIN ${ }^{1)}$ and Patrick WOLLANTS ${ }^{1)}$ \\ 1) Department of Metallurgy and Materials Engineering, Katholieke Universiteit Leuven, Kasteelpark Arenberg 44 box 2450 , \\ B-3001 Leuven, Belgium. E-mail: Muxing.Guo@mtm.kuleuven.be $\quad$ 2) Unité d'Ingénierie des Matériaux et des Procédés, \\ Université Catholique de Louvain, Place Sainte Barbe 2, B-1348 Louvain-la-Neuve, Belgium.
}

(Received on June 15, 2010; accepted on July 30, 2010)

\begin{abstract}
The phenomena taking place at the early stage of Al deoxidation were investigated with specific attention on the formation of $\mathrm{Al}_{2} \mathrm{O}_{3}$ inclusions. In a quartz tube, $\mathrm{Al}$ was exposed to liquid $\mathrm{Fe}$ containing different amounts of dissolved oxygen (ㅇ) for 1, 5, 30 and $60 \mathrm{~s}$. In this paper, quenched microstructures of the diffusion couple were examined to identify the interactions and the nature of the phases at the experimental temperature. They revealed that the reaction zone was composed of successive layers of Fe-Al intermetallic compounds, as predicted by the phase diagram of the system, i.e. $\alpha \mathrm{Fe}(\mathrm{Al}), \mathrm{FeAl}, \mathrm{FeAl}_{2}, \mathrm{Fe}_{2} \mathrm{Al}_{5}$ and $\mathrm{FeAl}_{3}$. Based on the microstructure, the concentration profiles, diffusion processes in solid and liquid phases, and the behavior of $\mathrm{Al}_{2} \mathrm{O}_{3}$ inclusions in the reaction zone, it was demonstrated that the reaction zone was completely liquid and that the solid Fe shell melted for the samples with holding time of 30 and $60 \mathrm{~s}$.
\end{abstract}

KEY WORDS: Fe-Al intermetallic compounds; deoxidation; Fe-Al-O ternary system; diffusion.

\section{Introduction}

Deoxidation of steel using aluminum (Al) is an essential step in secondary steelmaking for the production of clean steel. The dissolution behavior of $\mathrm{Al}$ in molten steel and the liquid steel flow pattern determine the location where $\mathrm{Al}$ is released and, therefore, the $\mathrm{Al}$ deoxidation yield. Due to the large temperature difference and the heat transfer between Fe and $\mathrm{Al}$, solid $\mathrm{Al}$ in contact with Fe heats up and partly melts. At the same time, liquid Fe solidifies at the interface, forming a shell. ${ }^{1)}$ This solid shell grows to a maximum thickness controlled by a heat transfer balance. ${ }^{2-4)}$ As the melting temperature of $\mathrm{Al}$ is much lower than that of steel, Al should melt completely inside the shell. ${ }^{5)}$ During the shell period, interactions between solid steel and liquid Al may lead to the formation of $\mathrm{Fe}-\mathrm{Al}$ intermetallic compounds with melting points intermediate between those of steel and Al. Once the solid shell melts, the content of the

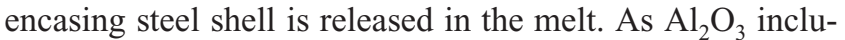
sion formation takes place in the vicinity of the $\mathrm{Al}$ addition, ${ }^{6}$ the dissolution behavior of $\mathrm{Al}$ influences the formation and the distribution of inclusions in terms of frequency, composition, size and morphology.

The phase diagram of the binary $\mathrm{Fe}-\mathrm{Al}$ system is shown in Fig. 1. ${ }^{7-9)}$ The left hand side of the diagram shows that the solubility of $\mathrm{Al}$ in fcc $\gamma$-Fe is limited to a few percents. In disordered bcc $\alpha$-Fe, up to $28 \mathrm{wt} \% \mathrm{Al}$ can be dissolved depending on temperature. The corresponding phase is noted $\alpha \mathrm{Fe}(\mathrm{Al})$ in this text. Intermetallic phase formation can occur from $12 \mathrm{wt} \% \mathrm{Al}$ on. Six non-stoichiometric intermetallic compounds are listed in the $\mathrm{Fe}-\mathrm{Al}$ binary system. Depending on the $\mathrm{Al}$ content and temperature, $\mathrm{Fe}_{3} \mathrm{Al}\left(\mathrm{DO}_{3}\right.$ -

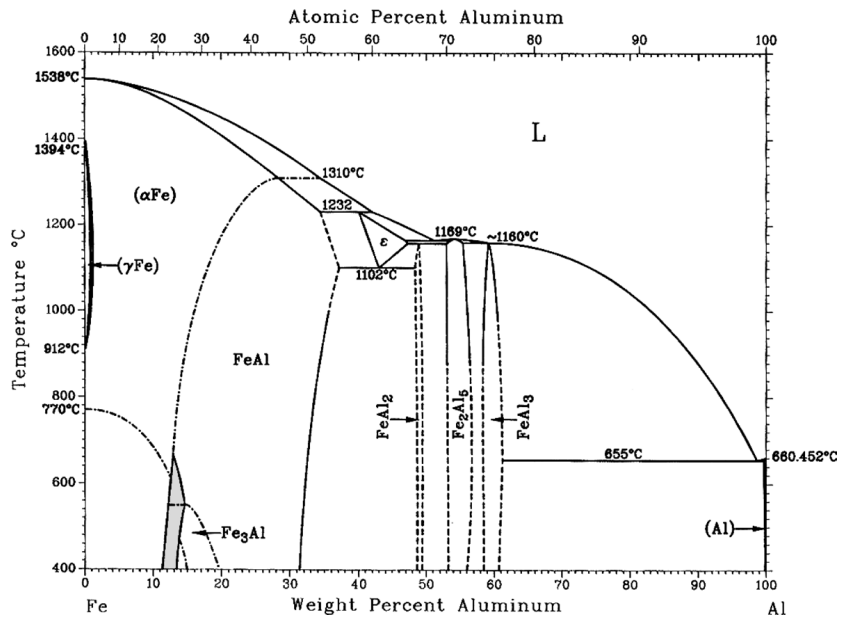

Fig. 1. Binary phase diagram of the $\mathrm{Fe}-\mathrm{Al}$ system. ${ }^{9}$

ordered), $\mathrm{FeAl}$ (ordered B2), $\mathrm{FeAl}_{2}, \mathrm{Fe}_{2} \mathrm{Al}_{3}(\varepsilon), \mathrm{Fe}_{2} \mathrm{Al}_{5}$ and $\mathrm{FeAl}_{3}$ are formed. Information on the physical, thermodynamic properties and phase reactions in the $\mathrm{Fe}-\mathrm{Al}$ system are provided by Shahverdi. ${ }^{10)}$ On the right hand side of the phase diagram, the solubility of $\mathrm{Fe}$ in solid $\mathrm{Al}$ is close to zero.

The microstructural analysis of interface layers that form when molten $\mathrm{Al}$ comes into contact with solid Fe or steel is mainly documented at temperatures ranging between 700 to $900^{\circ} \mathrm{C}^{10-14)}$ The interfacial reactions in this binary system have implications on many processes including aluminizing, mold casting, bimetals fabrication, joining and welding, etc. The types of interfacial phases formed, their morphology as well as their kinetics of growth were examined. 
The major intermetallic phase identified is $\mathrm{Fe}_{2} \mathrm{Al}_{5}$ close to the steel substrate. Minor phases were also reported, principally the formation of $\mathrm{FeAl}_{3}$ close to the solidified $\mathrm{Al}$. These studies highlight that the interfacial phases observed are not those given by the equilibrium phase diagram of the system. Some phases predicted by thermodynamic equilibrium are not found, indicating that the formation mechanisms and the diffusion conditions in the phases influence greatly the growth process and the overall interfacial structure at a given temperature.

This paper is the first part of an experimental study of the phenomena involved in the early steps of the deoxidation process, when $\mathrm{Al}$ rich melts are brought into contact with oxidized Fe for a very short time. It focuses on the comprehension of the interactions between $\mathrm{Al}$ and liquid $\mathrm{Fe}$ containing various dissolved oxygen contents of 160 to $1800 \mathrm{ppm}$ during the initial dissolution stage. These interactions define thermal history, mass transfer, concentration profiles and supersaturation degree, which determine the nucleation and growth conditions of the inclusions. The second part of the study ${ }^{15)}$ discusses in more detail the formation and the morphology of the inclusions formed at the onset of deoxidation.

\section{Experimental}

One hundred grams of electrolytic Fe $(99.97 \% \mathrm{Fe})$ was filled in an alumina crucible ( $30 \mathrm{~mm}$ ID, $35 \mathrm{~mm}$ OD, $50 \mathrm{~mm}$ $\mathrm{H})$ and placed inside a high temperature vertical tube furnace (GERO HTRV 100-250/18, $\mathrm{MoSi}_{2}$ heating elements) and melted at $1600^{\circ} \mathrm{C}$ under purified $\mathrm{Ar}$ atmosphere. The oxygen content in the off-gas was measured with a solid state ceramic oxygen sensor (Rapidox 2100, Cambridge Sensotec Ltd.). A typical value of the oxygen concentration in purified $\mathrm{Ar}$ is about $10^{-14} \mathrm{ppm}$. The temperature profile in the furnace ensures a hot zone, approximately $4 \mathrm{~cm}$ in length, in which the temperature varies by less than $\pm 1 \mathrm{~K}$. The oxygen content in the melt was adjusted by the addition of reagent grade iron oxide powder $\left(\mathrm{Fe}_{2} \mathrm{O}_{3}\right)$, followed by stirring with an $\mathrm{Al}_{2} \mathrm{O}_{3}$ rod. Since the impurity level of the electrolytic Fe is low, the dissolved oxygen $(\underline{\mathrm{O}})$ is assumed equal to the total oxygen content. The latter was determined by combustion analysis on the bulk Fe of the samples.

A piece of $\mathrm{Al}(99 \% \mathrm{Al})$ was cut in a cubic shape ( $\sim 5 \mathrm{~mm}$ side), ground, pickled in $5 \% \mathrm{NaOH}$ solution for $1 \mathrm{~min}$, followed by washing in demineralised water, rinsing in acetone and drying. The $\mathrm{Al}$ piece was placed inside a quartz tube $(8 \mathrm{~mm}$ inside diameter, $10 \mathrm{~mm}$ outside diameter). The last $3 \mathrm{~cm}$ of the quartz tube were narrower in order to fix the $\mathrm{Al}$ piece inside $(6 \mathrm{~mm}$ inside diameter, $8 \mathrm{~mm}$ outside diameter). After $30 \mathrm{~min}$ at $1600^{\circ} \mathrm{C}$ to stabilize the temperature of the melt, the quartz tube containing the Al piece was quickly introduced in the furnace and lowered into the liquid Fe. The Al piece was not preheated to avoid melting before the interaction. A small volume of molten Fe was sucked in the tube and brought into contact with Al (Fig. 2(a)). Except for sample 4, the contact between $\mathrm{Fe}$ and $\mathrm{Al}$ took place at the lower facet of the cubic piece of Al. In sample 4, the contact was made at a corner of the Al piece. During the interaction between $\mathrm{Fe}$ and $\mathrm{Al}$, the quartz tube

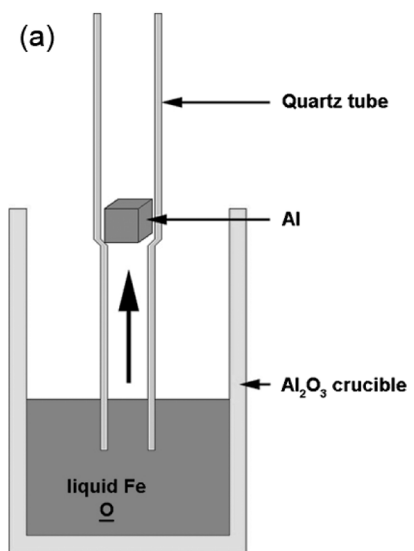

(b)

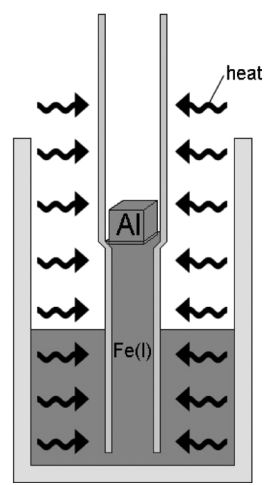

Fig. 2. Experimental setup: schematic representation of (a) Fe suction inside the quartz tube and (b) the material being subjected to heating during the interaction.

Table 1. Details of the experimental procedure and thickness of the intermetallic layers and of the reaction zone for each sample. The layers are delimited by the stability range of the phases: $\alpha \mathrm{Fe}(\mathrm{Al}): 0-26 \mathrm{wt} \% \mathrm{Al}$; FeAl: $26-33$ wt $\% \mathrm{Al} ; \mathrm{FeAl}+\mathrm{FeAl}_{2}: 33-48 \mathrm{wt} \% \mathrm{Al}$, Al-rich eutectic: $58 \mathrm{wt} \% \mathrm{Al}$.

\begin{tabular}{|c|c|c|c|c|c|c|c|}
\hline \multirow{2}{*}{ Sample } & Time & O content & \multicolumn{5}{|c|}{ Layer thickness $(\mu \mathrm{m})$} \\
\cline { 4 - 8 } & $(\mathrm{s})$ & $(\mathrm{ppm})$ & $\alpha \mathrm{Fe}(\mathrm{Al})$ & $\mathrm{FeAl}$ & $\mathrm{FeAl}+\mathrm{FeAl} \mathrm{F}_{2}$ & Al-rich eutectic & Reaction zone \\
\hline 1 & 30 & 160 & 220 & 270 & $200^{*}$ & - & $>1000$ \\
2 & 1 & 450 & $2-5$ & $2-5$ & $10-30^{*}$ & - & $50-100$ \\
\hline 3 & 1 & 780 & $2-5$ & $2-5$ & $10-30^{*}$ & - & $50-100$ \\
\hline 4 & 1 & 1800 & $20-25$ & 17 & $500-1000$ & mixed & $600-3000$ \\
\hline 5 & 5 & 1800 & 5 & $1-5$ & $10-15$ & 130 & 320 \\
\hline 6 & 60 & 1800 & 500 & 250 & 460 & 400 & $>2000$ \\
\hline \multicolumn{7}{|c}{ * with quenched eutectoid structure } \\
\hline
\end{tabular}

was maintained at that position in the liquid Fe, so that the material inside the tube was subjected to the furnace heat (Fig. 2(b)). After the desired reaction time, the quartz tube was rapidly withdrawn from the metal bath, removed from the furnace and quenched in water. Maximum $4 \mathrm{~s}$ elapsed during the sample withdrawal procedure. The contact time between liquid $\mathrm{Fe}$ and $\mathrm{Al}$ in the furnace hot zone varied from 1 to $60 \mathrm{~s}$. The conditions for each test are listed in Table 1.

The upper part of the samples was cut along the longitudinal axis and prepared for Scanning Electron Microscopy investigation (SEM XL30 FEG). The SEM is equipped with an EDS spectrometer from EDAX with a Super Ultra thin window allowing the analysis of light elements from B, with which concentration distributions were measured.

\section{Results}

\subsection{Macroscopic Observations}

Macroscopic examination of the samples after the interaction shows that mixing between $\mathrm{Fe}$ and $\mathrm{Al}$ was not complete, even after $1 \mathrm{~min}$. The $\mathrm{Al}$ piece has partially changed from the initial cube to a more rounded shape (Fig. 3). After $1 \mathrm{~s}$ interaction, the height of the remaining $\mathrm{Al}$ piece on top of Fe has not much changed (Fig. 3(a)). As a result of $\mathrm{Al}$ dissolution in $\mathrm{Fe}$, it has considerably decreased after $60 \mathrm{~s}$ of interaction (Fig. 3(b)).

\subsection{Evolution of the Reaction Zone Microstructure}

During the experiments, a diffusion couple is initiated between $\mathrm{Fe}$ and $\mathrm{Al}$ (Fig. 4). Interdiffusion of $\mathrm{Fe}$ and $\mathrm{Al}$ re- 


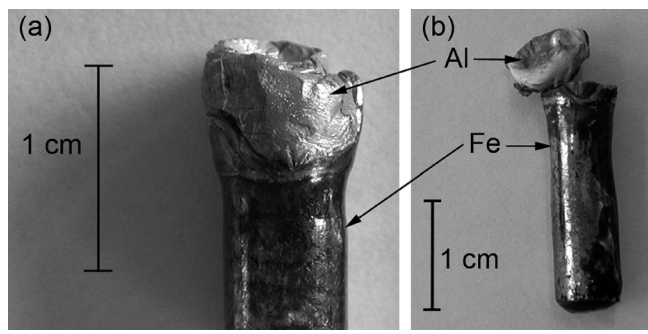

Fig. 3. Picture of the sample after (a) $1 \mathrm{~s}$ and (b) $60 \mathrm{~s}$ interaction with liquid Fe at $1600^{\circ} \mathrm{C}$. The $\mathrm{Al}$ piece is located on top and $\mathrm{Fe}$ lies beneath.

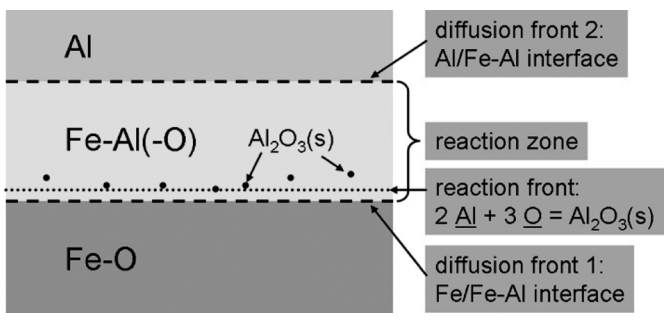

Fig. 4. Schematic view of the reaction zone development in the diffusion couple $\mathrm{Fe}-\mathrm{Al}(-\mathrm{O})$.

sults in the formation of a reaction zone ( $\mathrm{Fe}-\mathrm{Al})$, bounded by two diffusion fronts indicated by the dashed lines in Fig. 4. Diffusion front 1 is located at the interface between the reaction zone and Fe. Diffusion front 2 is located at the reaction zone/Al interface. We are mainly interested in the interactions occurring at diffusion front 1 . Therefore in this text, diffusion front refers to the $\mathrm{Fe} / \mathrm{Fe}-\mathrm{Al}$ interface.

The diffusion couple involves $\mathrm{O}$, which is present in the liquid Fe. Due to their high affinity, $\underline{\mathrm{Al}}$ and $\underline{\mathrm{O}}$ will react to form solid $\mathrm{Al}_{2} \mathrm{O}_{3}$ inclusions at the reaction front, which is indicated by the dotted line in Fig. 4. Since both $\underline{\mathrm{Al}}$ and $\underline{\mathrm{O}}$ must be available for the reaction to take place, the reaction front is located in the reaction zone. To simplify the microstructure description and the discussion, it is assumed that the $\mathrm{Al}_{2} \mathrm{O}_{3}$ formation reaction is instantaneous, that equilibrium is reached and that $\underline{\mathrm{Al}}$ and $\underline{\mathrm{O}}$ equilibrium compositions are negligibly small. With these assumptions, the position of the reaction front corresponds to that of the diffusion front, as will be shown during the investigation of the sample reaction zone.

The reaction zone consists of several product layers composed of intermetallic compounds in a sequence dictated by the phase diagram. ${ }^{16)}$ The various product layers between the Al-rich region and bulk Fe were identified by SEM and EDS analysis. Based on the occurrence, the morphology and the composition of the product layers, differences were noticed between samples 1 to 3 with lower initial $\underline{\mathrm{O}}$ content $(160-780 \mathrm{ppm})$ and samples 4 to 6 with higher initial $\underline{\mathrm{O}}$ content (1 $800 \mathrm{ppm})$.

The cross section of sample $2(450 \mathrm{ppm} \underline{\mathrm{O}}$ and $1 \mathrm{~s}$ interaction time) is shown in Fig. 5(a). The Al-rich side contains a needle-shaped Fe-rich phase. The composition of this phase ranges between 16 and $38 \mathrm{wt} \% \mathrm{Fe}$, depending on the location (effect of Al matrix excitation). The Al matrix, indicated by the dark phase in Fig. 5(b), contains less than $2 \mathrm{wt} \% \mathrm{Fe}$.

The sequence and morphology of the product layers were

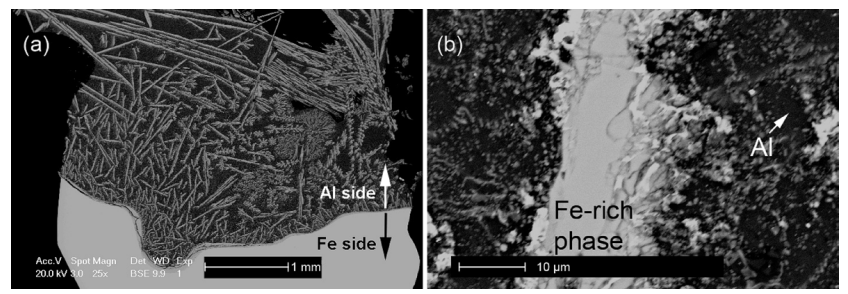

Fig. 5. (a) Overview of the cross section of sample 2 (see Table 1) after contacting $\mathrm{Fe}$ with a piece of $\mathrm{Al}$; (b) enlarged view of the needle-shaped Fe-rich phase in the Al.

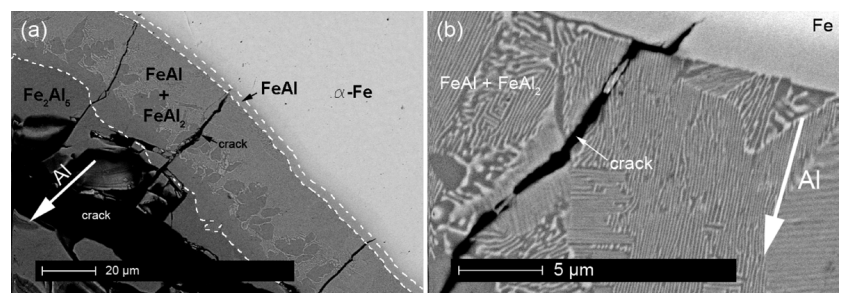

Fig. 6. BSE images of the reaction zone between $\mathrm{Al}$ and Fe after $1 \mathrm{~s}$ interaction time (sample 3,780 ppm $\underline{\mathrm{O}}$ ): (a) occurrence of intermetallic layers between $\mathrm{Fe}$ and Al-rich area, the dotted lines indicating the boundary of the intermetallic layers; (b) the fine quenched eutectoid structure of the two-phase layer $\mathrm{FeAl}+\mathrm{FeAl}_{2}$. The white arrows indicate the direction of the $\mathrm{Al}$ side.

identical for samples 2 and 3 with relatively low $\underline{\mathrm{O}}$ content (respectively, $450 \mathrm{ppm}$ and $780 \mathrm{ppm}$ ) and $1 \mathrm{~s}$ interaction time. The reaction zone of sample 3 is shown in Fig. 6(a). The thickness of the intermetallic layers is listed in Table 1. Close to the $\mathrm{Al}$ side, a $\mathrm{Fe}_{2} \mathrm{Al}_{5}$ layer with an average composition $54 \mathrm{wt} \% \mathrm{Al}$ and $46 \mathrm{wt} \% \mathrm{Fe}$ was found in samples 2 and 3 (Fig. 6(a)). In sample 1 with low $\underline{\mathrm{O}}$ content (160 ppm) and $30 \mathrm{~s}$ interaction time, successive layers of $\mathrm{FeAl}_{2}, \mathrm{Fe}_{2} \mathrm{Al}_{5}$ and $\mathrm{FeAl}_{3}$, mostly dendritic shaped, as well as quenched liquid were identified based on EDS measurements. In samples 1 to 3, a composite layer was observed near the Fe-rich side, as shown in Fig. 6 and Fig. 7(b), for, respectively, sample 3 and sample 1 . This phase has an average composition of $42.6 \mathrm{wt} \% \mathrm{Al}$, corresponding to $\mathrm{Fe}_{2} \mathrm{Al}_{3}$ ( $\varepsilon$ phase). Below $1100^{\circ} \mathrm{C}$, this compound transforms into the compounds $\mathrm{FeAl}$ and $\mathrm{FeAl}_{2}$ (eutectoid reaction). Higher resolution images of this intermetallic layer show that a fine eutectoid structure has formed (Fig. 6(b)), probably during quenching at the end of the experiment. Based on its composition ranging between 26 and $35 \mathrm{wt} \% \mathrm{Al}$, the orderedB2 FeAl phase layer was identified next to the two-phase $\mathrm{FeAl}+\mathrm{FeAl}_{2}$ layer towards the Fe-rich side. In the direction of the Al-rich area, the BSE contrast reveals that the FeAl grains in sample 1 are surrounded by a brighter phase (Fig. 7(b)), presumably richer in Fe. This secondary phase would have a higher melting point than the $\mathrm{FeAl}$ phase due to the higher Fe content, indicating that this structure is formed during quenching of the liquid. Finally, $\alpha \mathrm{Fe}(\mathrm{Al})$ with a composition ranging from 0 to $26 \mathrm{wt} \% \mathrm{Al}$ and thickness listed in Table 1 was identified between the diffusion front and the FeAl product layer (Figs. 6(a) and 7(a)).

The Al-rich intermetallic layer sequence (above $60 \mathrm{wt} \%$ Al) in the samples with high initial $\underline{\mathrm{O}}$ content (samples 4 to $6,1800 \mathrm{ppm} \underline{\mathrm{O}}$ ) is similar to that observed in samples 1 to 
3 (Figs. 8(a), 9(c) and 10(a), and Table 1). The main difference compared to the samples 1 to 3 is the presence of, towards the Fe-rich areas, a two-phase layer consisting of an $\mathrm{Al}$-rich eutectic $\left(\mathrm{FeAl}_{3}-\mathrm{Fe}_{2} \mathrm{Al}_{5}\right.$ at approximately $58 \mathrm{wt} \% \mathrm{Al}$, $1160^{\circ} \mathrm{C}$ ), with a very fine eutectic structure formed during quenching (Figs. 8(b), 9(b) and 9(c)). Between the $\alpha \mathrm{Fe}(\mathrm{Al})$ and the two-phase layer (Fig. 8(b)), two layers can be iden-
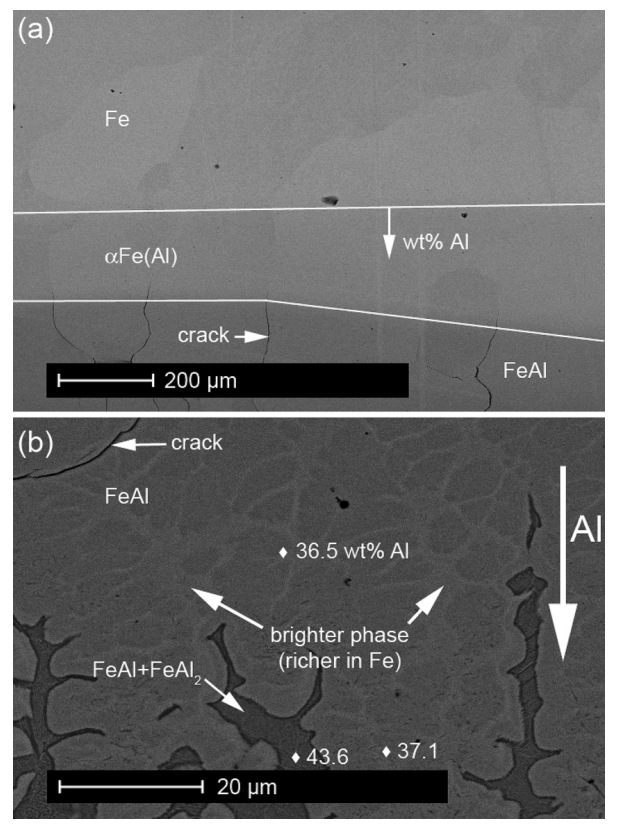

Fig. 7. BSE images of the reaction zone between $\mathrm{Al}$ and Fe after 30 s interaction time (sample 1, $160 \mathrm{ppm}$ O): (a) overview of the diffusion front area and (b) interface between the $\mathrm{FeAl}$ phase and the eutectoid phase $\mathrm{FeAl}+\mathrm{FeAl}_{2}$. The thick white arrow indicates the direction of the $\mathrm{Al}$ side.
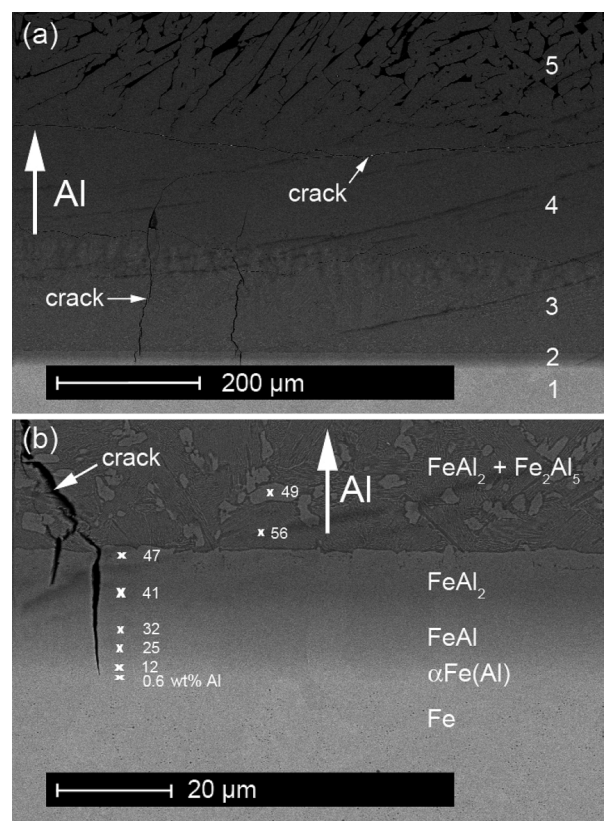

Fig. 8. $\mathrm{BSE}$ images of the reaction zone between $\mathrm{Al}$ and $\mathrm{Fe}$ after $5 \mathrm{~s}$ interaction time (sample 5, $1800 \mathrm{ppm}$ O). (a) 1: Fe; 2 : thin layers of $\mathrm{FeAl}$ and $\mathrm{FeAl}_{2} ; 3$ : Al-rich eutectic $\left(\mathrm{Fe}_{2} \mathrm{Al}_{5}-\mathrm{FeAl}_{3}\right) ; 4: \mathrm{FeAl}_{3} ; 5: \mathrm{FeAl}_{3}+\mathrm{Al}$; (b) enlarged view of the diffusion front between $\mathrm{Fe}$ and the Al-containing area. The thick white arrow indicates the direction of the Al side. tified by the BSE contrast. The lower layer consists of FeAl and the upper layer has a composition lying in the domains $\mathrm{FeAl}+\mathrm{FeAl}_{2}$ and $\mathrm{FeAl}_{2}$. The thickness of the layers in samples 4 to 6 is provided in Table 1. Neither microsegregation nor a eutectoid structure was detected in these layers (Figs. 8(b), 9(a) and 9(b)). As regards sample 4, contact between $\mathrm{Fe}$ and the $\mathrm{Al}$ piece was made at a corner of the $\mathrm{Al}$ piece,

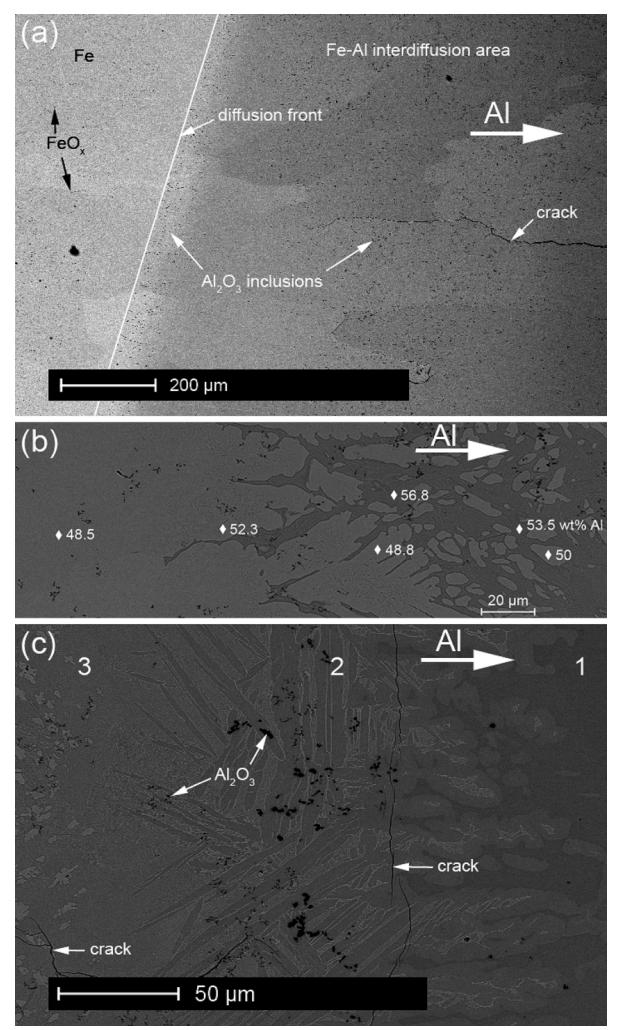

Fig. 9. BSE images of the reaction zone in sample $6(60 \mathrm{~s}$ interaction time, $1800 \mathrm{ppm}$ O). The $\mathrm{Al}$ rich side is on the right side: (a) overview of the reaction zone near the diffusion front. Black spots in the $\mathrm{Fe}-\mathrm{Al}$ interdiffusion area are $\mathrm{Al}_{2} \mathrm{O}_{3}$ inclusions; (b) enlarged view of the interface between quenched liquid and the Al-rich eutectic on the right hand side; (c) reaction zone showing the Al-rich eutectic (3), the dendritic $\mathrm{FeAl}_{3}$ phase (2) and the quenched liquid phase (1). The thick white arrow indicates the direction of the $\mathrm{Al}$ side.
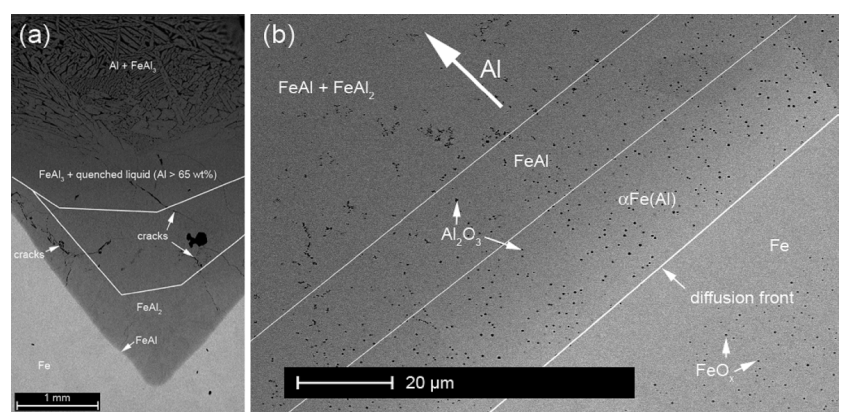

Fig. 10. BSE images of the reaction zone in sample 4 ( $1 \mathrm{~s}$ interaction time, $1800 \mathrm{ppm} \mathrm{O}$ ): (a) overview of the interaction area, from the bulk Fe (bottom) to the Al-rich region (top); (b) enlarged view of the $\mathrm{Fe}-\mathrm{Al}$ interdiffusion area, showing the diffusion front and the solidified intermetallic layers. The white lines delimit the different intermetallic layers. The thick white arrow indicates the direction of the $\mathrm{Al}$ side. 
resulting in Fe penetrating deeper in the Al, as seen in Fig. 10(a). Though the sequence and the morphology of the solidified intermetallic layers are identical to those in samples 5 and 6, the layers are much thicker compared to other samples with similar holding time, as seen in Table 1. Owing to the high initial $\underline{\mathrm{O}}$ content in the $\mathrm{Fe}$, numerous $\mathrm{Al}_{2} \mathrm{O}_{3}$ inclusions are found distributed through the solidified intermetallic layers (Figs. 9 and 10(b)). Near the diffusion front, the inclusions are mostly individual (Figs. 9(a) and 10(b)). In sample 5, nm sized $\mathrm{Al}_{2} \mathrm{O}_{3}$ inclusions were found (see Sec. 3.3, Fig. 12(a)). Those in samples 4 and 6 have an average size of, respectively, 0.7 and $2 \mu \mathrm{m}$ (Fig. 12(b) and 12(c)). Towards the Al-rich area, $\mathrm{Al}_{2} \mathrm{O}_{3}$ inclusions tend to form aggregates (Figs. 9(b), 9(c), and 10(b)).

\subsection{Concentration Gradient}

Figure 11 shows the Al concentration profile measured on the samples with various interaction time and initial $\underline{\mathrm{O}}$ contents as a function of the distance from the diffusion front. The concentration profile was measured perpendicular to the diffusion front. With a contact time of 1 or $5 \mathrm{~s}$ (samples 2 and 5, Fig. 11(a)), the Al profiles, which are shown only for the first $100 \mu \mathrm{m}$, are very steep until the first $20 \mu \mathrm{m}$. The concentration is then slowly increasing. The effect of the initial $\underline{\mathrm{O}}$ content is hardly noticeable. The less steep $\mathrm{Al}$ concentration profile near the diffusion front measured in sample 4 is due to a different position of the $\mathrm{Al}$ inside the quartz tube, creating a two-dimensional and thereby faster diffusion process compared to the other samples. The Al profile in sample 3 is not shown due to lack of measurement data.

Figure 11(b) shows part of the Al concentration profiles in samples 1 and 6, with a longer interaction time. The Al profile extended over a larger area due to longer diffusion time compared to samples 2 to 5 . The concentration profile for sample $1(30 \mathrm{~s}, 160 \mathrm{ppm} \mathrm{O})$ is steep over approximately $100 \mu \mathrm{m}$ near the diffusion front, though less steep compared to samples 2 to 5 . At a distance between 100 and $170 \mu \mathrm{m}$ from the diffusion front, it remains almost constant at $10 \mathrm{wt} \% \mathrm{Al}$. Beyond that point, the $\mathrm{Al}$ concentration increases significantly again. The fluctuations in the concentration profiles are due to local inhomogeneities, especially with the presence of two-phase layers. The shape of the Al profile of sample $6(60 \mathrm{~s}, 1800 \mathrm{ppm})$ is similar to that of sample 1, yet different in magnitude. The Al profile is steep within approximately $120 \mu \mathrm{m}$, remains nearly constant at approximately $21 \mathrm{wt} \% \mathrm{Al}$ for another $10 \mu \mathrm{m}$ and increases again, almost linearly. Near the interface, the Al profile of sample 6, with longer interaction time, is steeper than that of sample 1, with shorter holding time. With an identical diffusion process, the profile at the interface is expected to become less steep with holding time. It is believed that the difference comes from the $\underline{\mathrm{O}}$ content in the bulk Fe which is significantly higher in sample 6 .

Because the $\underline{\mathrm{O}}$ level in the Fe matrix was below the detection limit of the EDS system, the $\underline{\mathrm{O}}$ concentration profile near the interface could not be quantified. However, for samples 4, 5 and 6 in which the initial $\underline{O}$ content of the liquid Fe was high, the presence of an $\underline{\mathrm{O}}$ gradient near the interface is suggested by the formation of a "precipitate-free" zone separating the $\mathrm{Fe}-\mathrm{O}$ from the $\mathrm{Fe}-\mathrm{Al}$ domain (Fig. 12). In the $\mathrm{Fe}-\mathrm{O}$ domain, numerous $\mathrm{FeO}_{x}$ inclusions are found, due to high $\underline{\mathrm{O}}$ content in liquid $\mathrm{Fe}$ and the decreasing $\underline{\mathrm{O}}$ solubility in Fe with temperature. The absence of precipitates means therefore a lower $\underline{\mathrm{O}}$ content at high temperature. The extent of liquid Fe with low $\underline{\mathrm{O}}$ content is determined by the
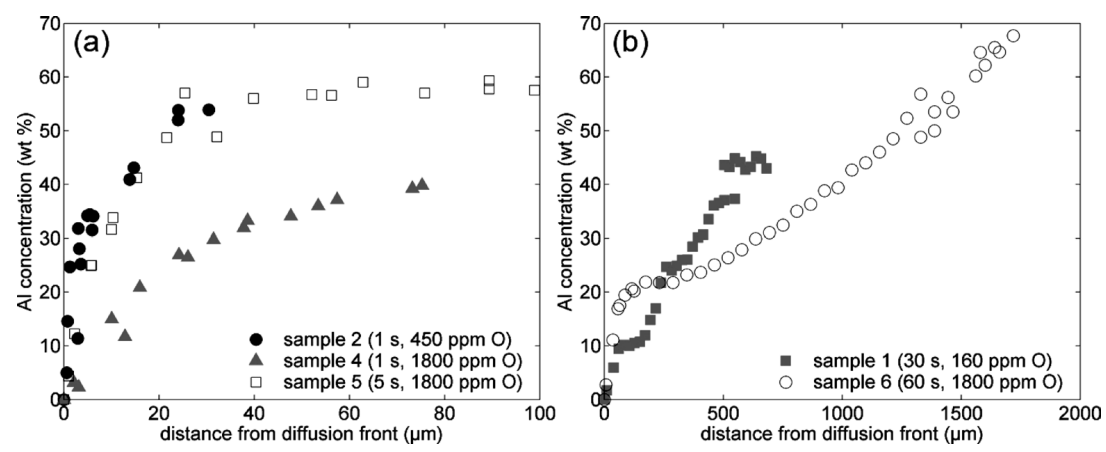

Fig. 11. $\mathrm{Al}$ concentration profile at the $\mathrm{Fe} / \mathrm{Fe}-\mathrm{Al}$ interdiffusion front, measured with SEM-EDS for samples (a) with short interaction time and (b) with longer interaction time.
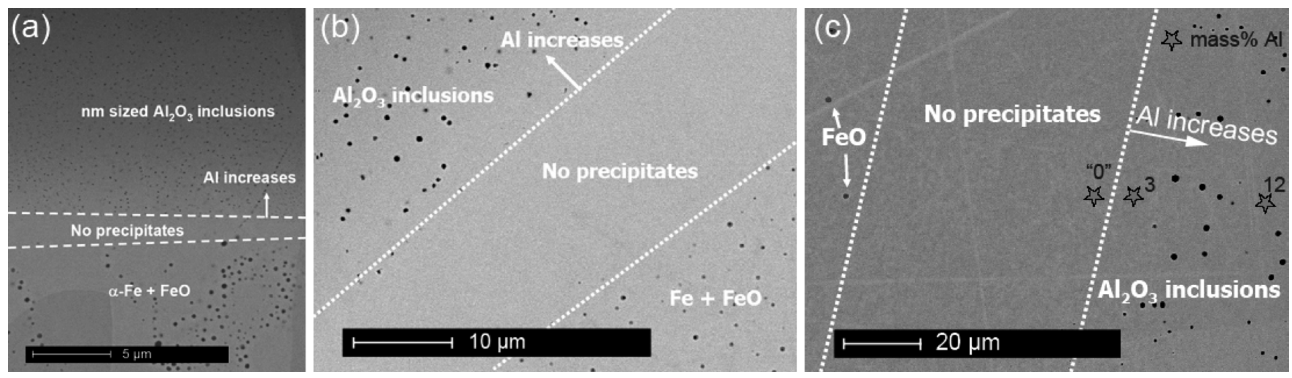

Fig. 12. Overview of the $\mathrm{Fe} / \mathrm{Fe}-\mathrm{Al}$ diffusion front showing the precipitate-free zone (delimited by the dotted lines) separating the pure $\mathrm{Fe}$ region containing $\mathrm{FeO}_{x}$ precipitates from the $\mathrm{Fe}-\mathrm{Al}$ region containing $\mathrm{Al}_{2} \mathrm{O}_{3}$ inclusions for samples (a) 5 , (b) 4 and (c) 6 . 
thickness of the precipitate-free zone. As most of the mass transport under the experimental conditions is assumed to be driven mainly by diffusion processes, a thin precipitatefree zone corresponds to a steep $\underline{\mathrm{O}}$ concentration profile near the diffusion front. In the $\alpha \mathrm{Fe}(\mathrm{Al})$ layer next to the interface, only $\mathrm{Al}_{2} \mathrm{O}_{3}$ inclusions are found, resulting from the diffusion of $\mathrm{Fe}, \underline{\mathrm{Al}}$ and $\underline{\mathrm{O}}$ and the deoxidation reaction at the diffusion front when $\underline{\mathrm{Al}}$ and $\underline{\mathrm{O}}$ meet. As seen in Fig. 12, the thickness of the precipitate-free zone is clearly varying between the samples. For sample 5, this zone is 1.5 to $2.5 \mu \mathrm{m}$ thick (Fig. 12(a)), whereas it reaches approximately $17 \mu \mathrm{m}$ for sample 4 (Fig. 12(b)) and $63 \mu \mathrm{m}$ for sample 6 (Fig. 12(c)). After comparing these values with the $\mathrm{Al}$ concentration profiles given in Fig. 11, the precipitate-free zones tend to be thinner when the $\underline{\mathrm{Al}}$ gradient is steeper near the interface. The latter is due to the deoxidation reaction taking place at the interface, which determines the relation between the $\underline{\mathrm{O}}$ and the $\underline{\mathrm{Al}}$ gradients at both sides of the diffusion front in order to satisfy the mass balance at the diffusion front and the reaction stoichiometry.

\section{Discussion}

\subsection{Mass Transport of Fe in the Al-rich Region}

Bouché et al. ${ }^{12)}$ also observed a thin needle-shaped $\mathrm{FeAl}_{3}$ phase uniformly dispersed in the $\mathrm{Al}$ matrix. The formation of these crystals is attributed to a eutectic reaction during solidification of liquid Al containing some dissolved Fe. Rapid solidification conditions in hypereutectic Al alloys containing Fe can lead to the formation of Al solid solution as primary phase to solidify, with intermetallics forming in the intercellular region. ${ }^{17)}$ This transition is due to kinetic effects.

The presence of Fe in the Al solid solution is an indication that diffusion of $\mathrm{Fe}$ in $\mathrm{Al}$ occurred even when the immersion time was very short. The diffusion of $\mathrm{Fe}$ atoms in the Al-rich area seems to be much faster than the conventional diffusion process. According to Shahverdi et al., ${ }^{10)} \mathrm{Fe}$ is brought to the Al-rich area through the breakage, flotation, re-melting and dissolution of $\mathrm{FeAl}_{3}$ into molten $\mathrm{Al}$. Under the present conditions, the flotation of Al-rich intermetallics in liquid Al seems not possible owing to their higher densities compared to liquid Al. ${ }^{18)}$ Instead, turbulent flow might be initiated by the large temperature difference between liquid $\mathrm{Fe}$, initially at $1600^{\circ} \mathrm{C}$, and solid $\mathrm{Al}$, initially at $25^{\circ} \mathrm{C}$, combined with the furnace heat surrounding the quartz tube (Fig. 2(b)) and reheating the charge. In the case of turbulent flow, mixing is significantly accelerated and Fe can be transported faster in the liquid phase. This mechanism is likely responsible for the Fe transport to the Al-rich region, indicating that the latter was in the liquid state during the interaction.

$\mathrm{Si}$ was not measured (or detected) in Fe nor in $\mathrm{Al} . \mathrm{SiO}_{2}$ from the quartz tube could not be reduced by $\mathrm{Al}$ due to the short contact time and the limited contact surface between $\mathrm{Al}$ and the quartz tube.

\subsection{Influence of $\underline{\boldsymbol{O}}$ on the Diffusion Process and the Microstructure}

The influence of $\underline{\mathrm{O}}$ on the $\mathrm{Al}$ concentration profiles was noticeable for samples 1 and 6 with longer holding times.
As shown in Fig. 11(b), an increase in the $\underline{\mathrm{O}}$ content seems to slow down the $\mathrm{Al}$ penetration, resulting in a steeper $\mathrm{Al}$ concentration profile compared to the case with low $\underline{\mathrm{O}}$. Since Al cannot diffuse in oxidized $\mathrm{Fe}, \underline{\mathrm{O}}$, which is transported faster than $\mathrm{Al}$ towards the diffusion front by concentration gradient and surface tension effects, must be consumed by the reaction before $\mathrm{Al}$ can diffuse further. The process of $\mathrm{Al}$ penetration is therefore hindered with higher $\underline{\mathrm{O}}$ content, resulting in a steeper $\mathrm{Al}$ profile near the diffusion front.

The two-phase layer $\mathrm{FeAl}+\mathrm{FeAl}_{2}$ with a eutectoid structure in samples 1 to 3 (Fig. 6(b)) was not observed in samples 4 to 6 . Instead, a single homogeneous phase was found in that composition range and an Al-rich eutectic formed the Al-richer area. The reasons for this are not clear. The main differences between these samples are the $\underline{\mathrm{O}}$ content and the numerous $\mathrm{Al}_{2} \mathrm{O}_{3}$ inclusions distributed in most of the solidified layers. The presence of $\mathrm{Al}_{2} \mathrm{O}_{3}$ inclusions brings an additional element in the system, $\mathrm{O}$. The ternary system $\mathrm{Fe}-\mathrm{Al}-\mathrm{O}$ should be considered instead of the binary system $\mathrm{Fe}-\mathrm{Al}$. In some alloys, such as Al-Ti alloys, ${ }^{19)} \mathrm{O}$ influences the solidification behavior by shifting phase transitions and extending stability domains compared to binary systems. Further work is needed to clarify the influence of $\mathrm{O}$ on the solidification behavior in $\mathrm{Fe}-\mathrm{Al}$ alloys.

\subsection{Identification of the Solid and Liquid Phases at Experiment Temperature \\ 4.3.1. Reaction Zone}

It was shown in Sec. 4.1 that the upper Al-rich part of the sample should be in the liquid state to enable fast transport of Fe in liquid Al. The observation of the microstructures revealed a typical quenched-liquid structure in all samples, especially in the eutectic and eutectoid composition range. Considering that the quenched eutectoid structure forms during solidification of the $\varepsilon$ phase $\left(\mathrm{Fe}_{2} \mathrm{Al}_{3}\right)$, the local temperature during the experiment should have been at least $1102^{\circ} \mathrm{C}$, according to the $\mathrm{Fe}-\mathrm{Al}$ phase diagram (Fig. 1). Moreover, assuming that the region of the sample with a composition lying in the $\mathrm{FeAl}_{3}$ domain was liquid, the temperature in that area should have been above $1160^{\circ} \mathrm{C}$ according to the $\mathrm{Fe}-\mathrm{Al}$ phase diagram (Fig. 1). No evidence of a liquid, solid or mushy zone was found for the $\alpha \mathrm{Fe}(\mathrm{Al})$ and FeAl layers.

The growth rate of the intermetallic layers during interaction between solid $\mathrm{Fe}$ and liquid $\mathrm{Al}$ is documented in the temperature range of 700 to $1050^{\circ} \mathrm{C} \cdot{ }^{10-13,20-25)}$ After $1 \mathrm{~min}$ hot-dip aluminizing treatment at $800^{\circ} \mathrm{C}$, the maximum reported layer thickness consisting of $\mathrm{Fe}_{2} \mathrm{Al}_{5}$ is about $200 \mu \mathrm{m} .{ }^{12)}$ It attains about $700 \mu \mathrm{m}$ after $45 \mathrm{~min}$ at $800^{\circ} \mathrm{C} .{ }^{11)}$ After a diffusion treatment of the aluminized specimen during $15 \mathrm{~min}$ at $1000^{\circ} \mathrm{C}, \alpha \mathrm{Fe}(\mathrm{Al})$ and $\mathrm{FeAl}$ layers were formed and attained a thickness of, respectively, 32 and $16 \mu \mathrm{m} .{ }^{20,21)}$ The growth kinetics of the intermetallic layers is reported to be diffusion-controlled, following a general parabolic equation ${ }^{11-13,20,25)}$ from which activation energies for the growth of $\mathrm{Fe}_{2} \mathrm{Al}_{5}, \mathrm{FeAl}$ and $\alpha \mathrm{Fe}(\mathrm{Al})$ were evaluated. The thickness of $\alpha \mathrm{Fe}(\mathrm{Al})$ and $\mathrm{FeAl}$ heated at, respectively, $1811 \mathrm{~K}$ and $1583 \mathrm{~K}$, which are the respective melting point of these compounds, were calculated for diffusion times of 35 and $65 \mathrm{~s}$ (samples 1 and 6), using the reported growth 
Table 2. Comparison of the calculated and measured thickness of $\alpha \mathrm{Fe}(\mathrm{Al})$ and $\mathrm{FeAl}$ for samples 1 and 6. The calculations were performed using growth law relations from Sasaki and Yakou ${ }^{20)}$ at $T=1811 \mathrm{~K}$ for $\alpha \mathrm{Fe}(\mathrm{Al})$ and at $T=1583 \mathrm{~K}$ for $\mathrm{FeAl}$.

\begin{tabular}{|l|c|c|c|c|c|}
\hline & \multirow{2}{*}{ time (s) } & \multicolumn{2}{|c|}{$\alpha \mathrm{Fe}(\mathrm{Al})$ thickness $(\mu \mathrm{m})$} & \multicolumn{2}{c|}{ FeAl thickness $(\mu \mathrm{m})$} \\
\cline { 3 - 6 } & & calculated & measured & calculated & measured \\
\hline sample 1 & 35 & 99 & $\sim 220$ & 23.6 & $\sim 270$ \\
\hline sample 6 & 65 & 135 & $\sim 500$ & 32.2 & $\sim 250$ \\
\hline
\end{tabular}

law relations. ${ }^{20)}$ Five seconds were added in the calculations to consider the time during the sample withdrawal procedure. These temperatures and durations are employed in the calculations to obtain an estimate of the maximum possible layer thickness. As seen in Table 2, the calculated thickness is much smaller than the observed one, indicating that the reaction zone could not be formed entirely by growth of solid intermetallic compounds. Most of the reaction zone results from the solidification of a liquid phase, which corroborates the microstructure observations.

In binary systems, only single-phase intermetallic layers, which are separated by straight interfaces, can occur in the reaction zone under isothermal conditions. ${ }^{16)}$ In the present observations, some areas in the reaction zone consist of more than one single-phase. Also the Al concentration profile across the reaction zone is very gradual (Fig. 11), which is not the case for a binary diffusion couple with the reaction zone in the solid state. Both arguments suggest that the reaction zone consists of a liquid phase. Moreover, the presence of solid intermetallic layers at the diffusion front would have limited the diffusion of $\mathrm{Fe}$ to the liquid phase, which is in disagreement with the large mass transport of Fe observed in the samples.

Numerous $\mathrm{Al}_{2} \mathrm{O}_{3}$ inclusions were observed in the samples with high initial $\underline{\mathrm{O}}$ content. They were formed immediately behind the diffusion front. In the first tens of $\mu \mathrm{m}$ from the diffusion front, mainly individual inclusions were found (Figs. 9, 10 and 12). Beyond that point, the inclusions tend to form aggregates through a collision-coagulation mechanism (Figs. 9 and 10). A collision-coagulation mechanism implies that the inclusions could move, which indicate that the metal matrix was in the liquid state. At the position where the aggregates are observed, the $\mathrm{Al}$ content reaches $33 \mathrm{wt} \%$ for sample 4 and $20 \mathrm{wt} \%$ for sample 1 . The local temperature was therefore not less than, respectively, $1300^{\circ} \mathrm{C}$ and $1420^{\circ} \mathrm{C}$, according to the $\mathrm{Fe}-\mathrm{Al}$ phase diagram (Fig. 1). Moreover, the average size of the individual inclusions near the diffusion front attained 0.7 and $2 \mu \mathrm{m}$ in, respectively, samples 4 and 6 (Figs. 12(b) and 12(c)), which cannot be attributed to solid state precipitation. ${ }^{26)}$ This also corroborates that this area is most likely liquid.

To summarize the discussion on the reaction zone, it was shown that most of it was in the liquid state during the experiment. In the case of samples 1 and 6 with longer holding times and of sample 4, it was concluded that the reaction zone was completely liquid before quenching. In case of samples 2, 3 and 5, it is unsure whether the thin layers of $\mathrm{FeAl}$ and $\alpha \mathrm{Fe}(\mathrm{Al})$ next to the shell interface were liquid or solid.

\subsubsection{Solid Fe Shell}

The main consequence of the presence of a solid shell at the interface is the appearance of a significant discontinuity in the $\mathrm{Al}$ profile, owing to the large difference in mass transport between the liquid and the solid phase. The shell provides a barrier for the transport of $\mathrm{Al}$, creating a step in the concentration profile. The height of the step gradually decreases as Fe dissolution progresses, yet the discontinuity remains as long as the shell exists. A steep Al concentration profile was measured at the interface with samples 2 and 5 (Fig. 11(a)), which may be interpreted as a step, indicating the presence of the solid shell at the other side of the interface. The measured $\mathrm{Al}$ concentration profiles showed a different behavior for samples 1,4 and 6. The step was not present and the profiles exhibited a gradual increase in $\mathrm{Al}$ concentration. Al seemed to have diffused in Fe. This suggests that the solid Fe shell was not present anymore in samples 1 and 6 . Under the present conditions, the shell melting time was less than $30 \mathrm{~s}$.

In Sec. 3.3, it was shown that the presence of a precipitate-free zone suggests the formation of an $\underline{\mathrm{O}}$ gradient at the Fe side of the interface. The development of the $\underline{\mathrm{O}}$ concentration gradient in pure $\mathrm{Fe}$ implies that the $\underline{\mathrm{O}}$ should be able to be transported to some extent. The range of the diffusivity of $\underline{\mathrm{O}}$ in solid $\mathrm{Fe}^{27)}$ is in general comprised between $7 \cdot 10^{-5}$ to $7 \cdot 10^{-7} \mathrm{~cm}^{2} \cdot \mathrm{s}^{-1}$ in the temperature interval $1538-600^{\circ} \mathrm{C}$. In liquid $\mathrm{Fe}, D_{\mathrm{O}}$ is reported to be $1.4 \cdot 10^{-4} \mathrm{~cm}^{2} \cdot \mathrm{s}^{-1}$ at $1600^{\circ} \mathrm{C}^{28)}$ which is higher than in solid Fe. The $\underline{\mathrm{O}}$ content is very low in the cold Fe matrix (low solubility of $\underline{\mathrm{O}}$ in solid Fe, most of the $\mathrm{O}$ is present as $\mathrm{FeO}_{x}$ inclusions) and its diffusion in the solid phase is very limited. For that reason, one would expect the absence of the precipitate-free zone and the occurrence of $\mathrm{FeO}_{x}$ inclusions at the diffusion front if $\mathrm{Fe}$ was in solid state next to the $\mathrm{Fe} / \mathrm{Fe}-\mathrm{Al}$ diffusion front. From the experimental observations on the samples with high initial $\underline{\mathrm{O}}$ content (samples 4 to 6 ), it is clear that this precipitate-free zone exists and that $\underline{\mathrm{O}}$ diffusion took place from the $\underline{\mathrm{O}}$ rich area to the $\mathrm{Fe} / \mathrm{Fe}-\mathrm{Al}$ diffusion front. Considering the short interaction time, $\mathrm{Fe}$ in the precipitate free zone at the $\mathrm{Fe} / \mathrm{Fe}-\mathrm{Al}$ diffusion front was most likely in liquid state to allow $\underline{\mathrm{O}}$ to be transported at a sufficiently high rate.

\section{Conclusions}

Inside a quartz tube, a piece of $\mathrm{Al}$ was brought in contact for a short time $(1,5,30$ and $60 \mathrm{~s})$ with liquid Fe containing different $\underline{\mathrm{O}}$ levels at $1600^{\circ} \mathrm{C}$. The purpose was to investigate the interactions between $\mathrm{Fe}$ and $\mathrm{Al}$ shortly after the deoxidation stage, as these interactions control the nucleation and growth conditions of the inclusions. The present work examined the quenched microstructures of the diffusion couple to identify the interactions and the nature of the phases at the experimental temperature. The reaction zone consisted of several layers of Al-rich and Fe-rich intermetallic compounds of the $\mathrm{Fe}-\mathrm{Al}$ system.

Based on the microstructure, the concentration profiles, diffusion processes in solid and liquid phases, estimations of the intermetallic layer growth rates, and on the behavior of $\mathrm{Al}_{2} \mathrm{O}_{3}$ inclusions in the reaction zone, it was shown that the latter was completely liquid and that the solid Fe shell melted for the samples with holding time of 30 and $60 \mathrm{~s}$. For holding times of 1 and $5 \mathrm{~s}$, the liquid or solid nature of 
the thin layers of FeAl and $\alpha \mathrm{Fe}(\mathrm{Al})$, which are adjacent to the shell/reaction zone interface, could not be established.

\section{Acknowledgements}

The authors would like to thank ArcelorMittal Research and Development and the Belgian National Fund for Scientific Research (F.R.I.A.-F.N.R.S.) for their financial support.

\section{REFERENCES}

1) R. I. L. Guthrie, R. Clift and H. Henein: Metall. Trans. B, 6 (1975), 321.

2) S. A. Argyropoulos and R. I. L. Guthrie: Metall. Trans. B, 15 (1984), 47.

3) S. Sanyal, J. K. Saha, S. Chandra and C. Bhanu: ISIJ Int., 46 (2006), 779.

4) L. Pandelaers, F. Verhaeghe, B. Blanpain, P. Wollants and P. Gardin: Metall. Mater. Trans. B, 40 (2009), 676.

5) P. Gardin, J. F. Domgin, M. Simonnet and J. Lehmann: Rev. Metall. Cah. Inf. Tech., 105 (2008), 84.

6) K. Beskow, N. N. Viswanathan, L. Jonsson and Du Sichen: Metall. Mater. Trans. B, 32 (2001), 319

7) M. Palm: Intermetallics, 13 (2005), 1286.

8) M. Hansen: Constitution of Binary Alloys, MacGraw-Hill, New York, (1958), 90

9) U. R. Kettner: Binary Alloy Phase Diagrams, ASM International, Materials Park, OH, (1990), 147.

10) H. R. Shahverdi, M. R. Ghomashchi, S. Shabestari and J. Hejazi: J. Mater. Process. Technol., 124 (2002), 345.
11) A. Bouayad, C. Gerometta, A. Belkebir and A. Ambari: Mater. Sci. Eng. A, 363 (2003), 53.

12) K. Bouché, F. Barbier and A. Coulet: Mater. Sci. Eng. A, 249 (1998), 167.

13) H. R. Shahverdi, M. R. Ghomashchi, S. Shabestari and J. Hejazi: J. Mater. Sci., 37 (2002), 1061.

14) V. I. Dybkov: J. Mater. Sci., 25 (1990), 3615.

15) M. A. Van Ende, M. Guo, J. Proost, B. Blanpain and P. Wollants: ISIJ Int., 51 (2011), No. 1, in press.

16) A. A. Kodentsov, G. F. Bastin and F. J. J. van Loo: J. Alloys Comp., 320 (2001), 207.

17) D. M. Stefanescu: Science and Engineering of Casting Solidification, Springer, New York, (2009), 273.

18) Y. Plevachuk, I. Egry, J. Brillo, D. Holland-Moritz and I. Kaban: Int. J. Mat. Res., 98 (2007), 107.

19) J. Zollinger, J. Lapin, D. Daloz and H. Combeau: Intermetallics, 15 (2007), 1343.

20) T. Sasaki and T. Yakou: ISIJ Int., 47 (2007), 1016

21) T. Sasaki and T. Yakou: Surf. Coat. Technol., 201 (2006), 2131.

22) T. Sasaki and T. Yakou: J. Mater. Process. Technol., 197 (2008), 89.

23) Y. J. Li, J. Wang and X. Holly: Mater. Sci. Technol., 19 (2003), 657.

24) Y. J. Li, Y. L. Zhang and Y. X. Liou: J. Mater. Sci., 30 (1995), 2635.

25) S. Kobayashi and T. Yakou: Mater. Sci. Eng. A, 338 (2002), 44.

26) E. Schroer, S. Hopfe, P. Werner, U. Gösele, G. Duscher, M. Rühle and T. Y. Tan: Appl. Phys. Lett., 70 (1997), 327.

27) E. T. Turkdogan: Fundamentals of Steelmaking, Cambridge University Press, London, (1996), 134.

28) T. Iida and R. I. L. Guthrie: The Physical Properties of Liquid Metals, Clarendon Press, Oxford, (1993), 221. 